\title{
Determination of Standard Levels for Components of Health-Related Physical Fitness Using Computer Program
}

\author{
Dahoune Oumri, Atallah Ahmed, Tahar Tahar \\ University of Mostaganem, Algeria
}

\begin{abstract}
This study is aimed to design a computer program to assess the elements of health-related fitness for secondary students and determine their levels in the light of the proposed application software. To achieve this, the researchers adopted the descriptive style survey sample which was selected randomly from secondary students of some high schools of the state of Relizane who were numbered 2013 pupils. There has been using the battery tests which have included five tests, they are: body mass index, pacer test, push-up test, curl-up test and sit and reach test. The results have shown the effectiveness of the proposed software in the evaluation of the elements of health-related fitness at secondary school pupils to a large number of students in less time and effort and more accurate.
\end{abstract}

\section{Introduction}

We note during the recent years great importance and attention for physical activities by several researchers and specialists. This importance is not intended to compete but sport is considered as a mean of prevention and treatment.

So sport has become a necessity and an obligation for both genders and all classes, which modern scientific studies confirm on the importance of physical activity for man, psychological and organic health [1], [2]. In contrast the physical inactivity which causes serious problems such as heart disease, obesity, hypertension, anxiety and other diseases [3], [4]. Therefore, the level of physical activity in our society is a major need for health and preventive medicine.

Schools may play an important role in identifying children with low fitness via standardized field tests and promoting positive [5]. Physical fitness testing therefore can play an important role in firstly identifying potential health risk in individual adolescents and secondly promoting physical activity and educate adolescents in the importance of keeping fit and active [6].
In light of the overwhelming technological revolution that has taken over all areas, including education should be a reflection on the assessment as a component of the education system, it appeared the so-called technology assessment as a branch of technology education.

\section{Research terms}

Assessment: The measurement or assessment of health-related physical fitness is a fairly common practice by fitness professionals. There are several reasons to measure each component of healthrelated physical fitness. Some of the reasons are to:

- Educate individuals about their Current health-related physical fitness

- Motivate individuals towards more specific action/exercise [7], [8].

Health-related fitness components: Health-related physical fitness (HRPF) is demonstrated by a variety of factors including Body composition, cardiorespiratory fitness, musculoskeletal fitness (muscular strength and endurance) and flexibility [7]. Computer program: is a sequence of instructions, written to perform a specified task with a computer [9].

\section{Research issue}

The World Health Organisation and other world institutions' documents, namely the US Centre for Disease Control and Prevention, have recommended measuring the individual's physical activities and make people more sensitized to the importance of the physical activities for their well-being. We are also recommended to follow the accurate physical programs to be fit. The health and educational institutions all over the world have been urged to adopt and pursue new policies encouraging an active life and take an active part in fighting against the mounting diseases related to the individual's pattern of life in industrial countries and the developing ones as well [10]. 
Since the process of assessing the elements of the well-being-related physical fitness during the secondary education requires standard levels on which sports instructors depend so as to peer closely the levels of the physical efforts in regard to this category of age. A large number of researchers have noticed the absence of these standard levels; thus, they tried to find a new tool (the proposal of a computer program) which enables them to identify these needed standard levels and to know more about the level of health-related fitness amongst high-school students.

Due to the huge scientific and technological improvement, it is impossible to dismiss the educational process; we should go hand in hand with this evolution and be too compliant with it. It is palpable how important is the use of the computer in any assessment besides it is role in improving it saving more time, efforts and fees. As for time, the supervisor should not lose any of his instances in setting, correcting and reporting the exam scores and marks because these tasks will distract him from his main duty; hence, reaching an objective decision relies entirely on accurate operations.

\section{Objectives}

This study is aimed to:

1. Prepare battery of tests to the physical condition of high school students who meet the Algerian environment (our choice fell on tests validated by experts, who identified the first standards for adolescents 16 to 18 years in Algeria).

2. Designing a computer program to assess the elements of health-related fitness for secondary students.

3. Determination of health-related fitness standards of the secondary stage students.

\section{Methods and Materials}

To achieve this, researchers adopted the descriptive style survey sample which was selected randomly from secondary students of some high schools of the state of Relizane who were numbered 2013 pupils (1000 girls, 1013 boys).

\subsection{Measuring Physical Fitness}

There has been using the battery tests where there have been included five tests they are body mass index, pacer test, push-up test, curl-up test and sit and reach test.

These battery tests include a variety of healthrelated physical fitness tests that assess:

- Cardiovascular endurance: The ability of the circulatory and respiratory system to supply oxygen during sustained physical activity.
- Body composition: The relative amounts of muscle, fat, bone, and other vital parts of the body.

- Muscular strength: The ability of muscle to exert force.

- Muscular endurance: The ability of muscle to continue to perform without fatigue.

- Flexibility: The range of motion available at a joint [11].

The measurements of physical battery tests proposed in this study include most of the elements of the battery Fitnessgram.

For anthropometric measurements, subjects were barefoot. Weight was measured with a Medical Scales, height with a stadiomete.

\subsection{Computer program}

AlgeriaEva is a computer program specially designed to facilitate:

- determination of health-related fitness standards of the secondary stage students.

- assess elements of health-related fitness for secondary students.

- compare individual results with the results obtained by a team.

\subsubsection{Equations adopted in software.}

$\mathrm{BMI}=\mathrm{kg} / \mathrm{m} 2$ [12] for predicting $\mathrm{VO} 2$ max from the

Pacer test we used the formula :

VO2max $=41.77+($ pacer laps*0.49)-

$0.0029 *\left(\right.$ pacer laps $\left.{ }^{\wedge} 2\right)-(0.62 *$ bmi $)+0.35 *$

(age*gender) [13] include number of laps

completed, BMI $(\mathrm{kg} / \mathrm{m} 2)$, and gender ( 0 for girls,

1 for boys).

-Arithmetic mean, Standard deviation,

Minimum, Maximum ....

5.2.2. Programming language. Lua 5.1 [14]

Databases: initialization file.

5.2.3. Software platform. 32 bit, 64 bit Windows (Windows XP 7,8)

The following are the most important windows:

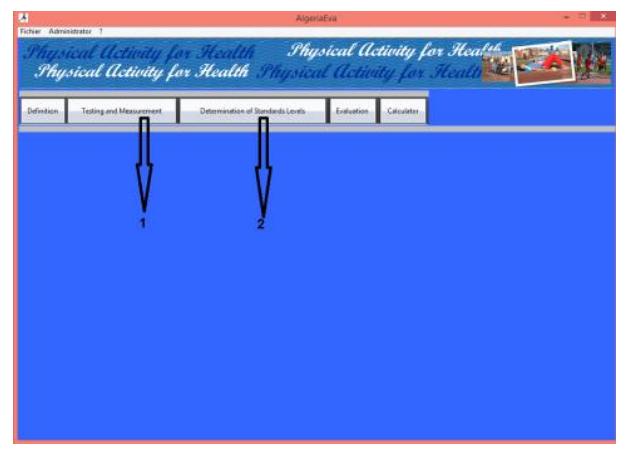

Figure 1. The main window of the program 
Key No. 1: When you press the key number (1) window appears showing the components of healthrelated fitness with an explanation of how to perform each test by video Figure 2.

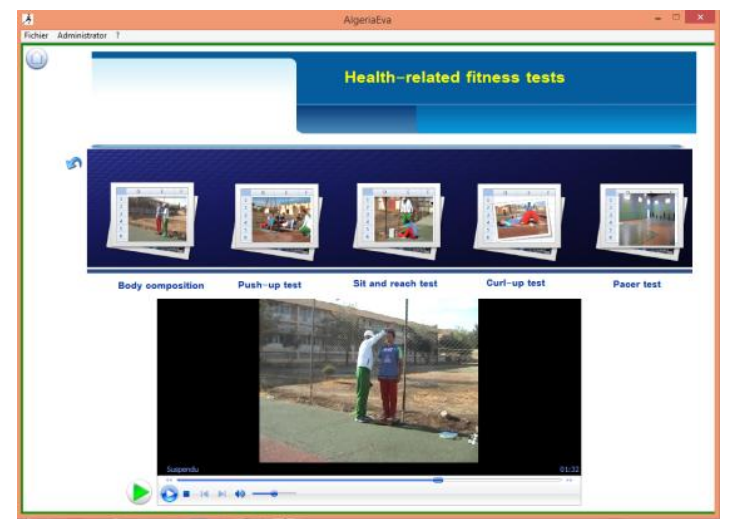

Figure 2. Window describes how to perform each test by video (assessment protocols).

Key No. 2: When you press the key number (2) window appears showing Figure 3.

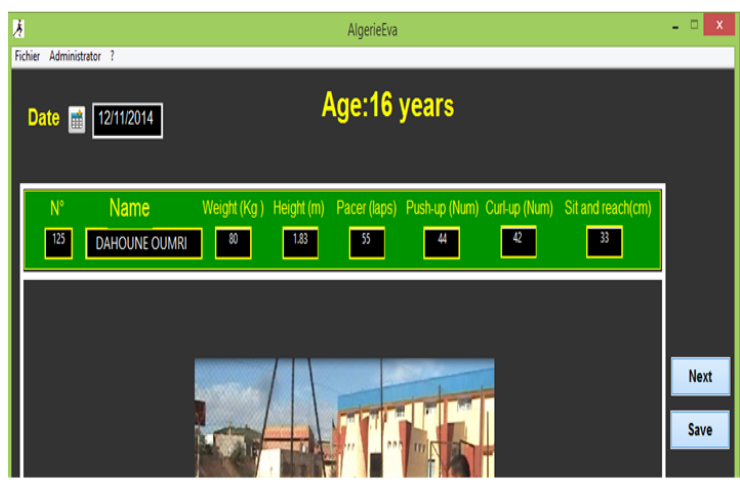

Figure 3. Window for enter the results of pupils in each test by age.

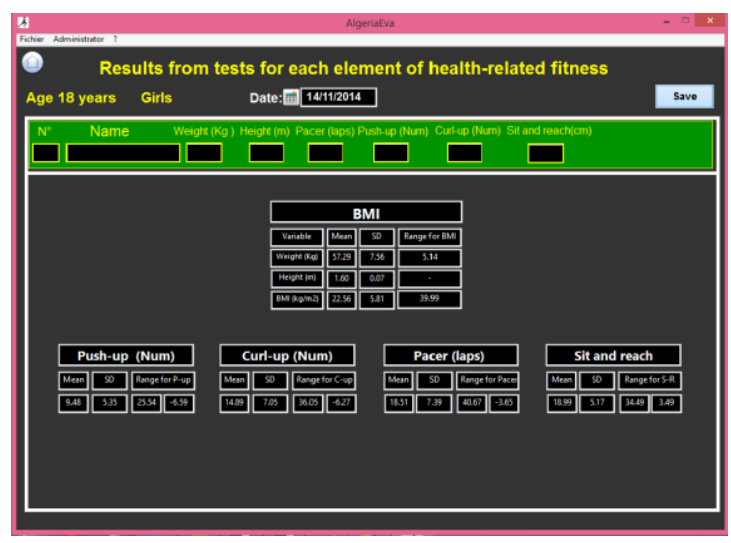

Figure 4. Window shows the Statistical treatment obtained by the program (by gender, age).

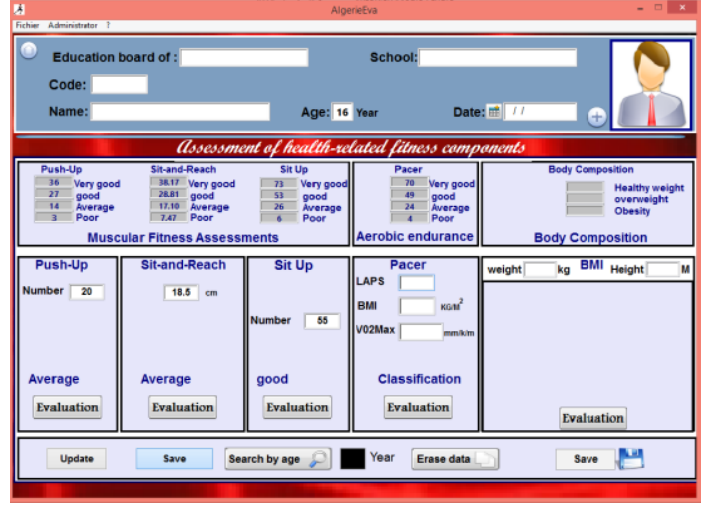

Figure 5. Individual assessment of each pupil, where this window allows the user to enter data on raw scores obtained in each test of the physical fitness and health-related tests.

\section{Results}

Correspondence tables: they indicate for each test the rating based on the result recorded. Initial referents scales are from the statistical treatment of a population of over 2013 students evaluated in 2014 in Relizane.

Normative data values were generated using AlgeiaEva program.

Table 1. Anthropometric profile for students 16 years (350 boys)

\begin{tabular}{|c|c|c|c|}
\hline Variable & Mean & $\begin{array}{c}\text { Standard } \\
\text { Deviation }\end{array}$ & $\begin{array}{c}\text { Range for } \\
\text { BMI }\end{array}$ \\
\cline { 1 - 3 } Height (m.) & 1.70 & 0.07 & \multirow{2}{*}{$\mathbf{1 3 . 7 1 - 2 8 . 4 6}$} \\
\cline { 1 - 3 } Weight (Kg) & 61,06 & 8,88 & \\
\hline BMI (kg/m2) & 21.08 & 2.46 & \\
\hline
\end{tabular}

Table 2. Anthropometric profile for students 16 years (300 girls)

\begin{tabular}{|c|c|c|c|}
\hline Variable & Mean & $\begin{array}{c}\text { Standard } \\
\text { Deviation }\end{array}$ & $\begin{array}{c}\text { Range for } \\
\text { BMI }\end{array}$ \\
\hline Height (m.) & 1.59 & 0.06 & \\
\hline Weight $(\mathbf{K g})$. & 50.76 & 7.14 & $\mathbf{4 . 5 7 - 3 5 . 5 6}$ \\
\hline BMI (kg/m2) & 20.07 & 5,16 & \\
\hline
\end{tabular}

Table 3. Anthropometric profile for students 17 years (350 boys)

\begin{tabular}{|c|c|c|c|}
\hline Variable & Mean & $\begin{array}{c}\text { Standard } \\
\text { Deviation }\end{array}$ & $\begin{array}{c}\text { Range for } \\
\text { BMI }\end{array}$ \\
\hline Height (m.) & 1.73 & 0.34 & \\
\hline Weight (Kg.) & 61.42 & 8.40 & $\mathbf{1 1 . 5 8 - 3 0 . 5 1}$ \\
\hline BMI (kg/m2) & 21,04 & 3,15 & \\
\hline
\end{tabular}


Table 4. Anthropometric profile for students 17 years (300 girls)

\begin{tabular}{|c|c|c|c|}
\hline Variable & Mean & $\begin{array}{l}\text { Standard } \\
\text { Deviation }\end{array}$ & $\begin{array}{c}\text { Range for } \\
\text { BMI }\end{array}$ \\
\hline Height (m.) & 1.59 & 0.08 & \multirow{3}{*}{$10.48-32.70$} \\
\hline Weight (Kg.) & 54.43 & 5.61 & \\
\hline BMI (kg/m2) & 21,59 & 3,70 & \\
\hline
\end{tabular}

Table 5. Anthropometric profile for students 18 years (313 boys)

\begin{tabular}{|c|c|c|c|}
\hline Variable & Mean & $\begin{array}{c}\text { Standard } \\
\text { Deviation }\end{array}$ & $\begin{array}{c}\text { Range for } \\
\text { BMI }\end{array}$ \\
\cline { 1 - 3 } Height (m.) & 1.72 & 0.07 & \multirow{2}{*}{$\mathbf{1 4 . 4 4 - 2 9 . 5 8}$} \\
\cline { 1 - 3 } Weight (Kg) & 65.15 & 8.61 & \\
\cline { 1 - 3 } BMI (kg/m2) & 22,01 & 2,52 & \\
\hline
\end{tabular}

Table 6. Anthropometric profile for students 18 years (400 girls)

\begin{tabular}{|c|c|c|c|}
\hline Variable & Mean & $\begin{array}{c}\text { Standard } \\
\text { Deviation }\end{array}$ & $\begin{array}{c}\text { Range for } \\
\text { BMI }\end{array}$ \\
\hline Height (m.) & 1.60 & 0.07 & \multirow{2}{*}{$\mathbf{0 5 . 1 4 - 3 9 . 9 9}$} \\
\cline { 1 - 3 } Weight (Kg.) & 57.29 & 7.56 & \\
\hline BMI (kg/m2) & 22,56 & 5,81 & \\
\hline
\end{tabular}

\section{Standard levels derived from software:}

Table 7.The following table is the norms for boys (16 years old students)

\begin{tabular}{|c|c|c|c|c|}
\hline Tests & $\begin{array}{c}\text { Pacer } \\
\text { (laps } \\
\text { competed) }\end{array}$ & Push-up & Curl-up & $\begin{array}{c}\text { sit } \\
\text { and reach } \\
(\mathbf{c m})\end{array}$ \\
\hline Level & & Number & \\
\hline Very good & $>69$ & $>35$ & $>72$ & $>38.16$ \\
\hline Good & $49-69$ & $\mathbf{2 7 - 3 5}$ & $\mathbf{5 3 - 7 2}$ & $\mathbf{2 8 . 8 1 - 3 8 . 1 6}$ \\
\hline Average & $\mathbf{2 4 - 4 8}$ & $\mathbf{1 4 - 2 6}$ & $\mathbf{2 6 - 5 2}$ & $\mathbf{1 7 . 1 0 - 2 8 . 8 0}$ \\
\hline Poor & $4-23$ & $\mathbf{0 3 - 1 3}$ & $\mathbf{0 6 - 2 5}$ & $\mathbf{7 . 4 7 - 1 7 . 0 9}$ \\
\hline Very poor & $<04$ & $<03$ & $<06$ & $<7.47$ \\
\hline & & & & \\
\hline
\end{tabular}

Table 8.The following table is the norms for girls (16 years old students)

\begin{tabular}{|c|c|c|c|c|}
\hline Tests & $\begin{array}{c}\text { Pacer } \\
\text { (laps } \\
\text { competed) }\end{array}$ & $\begin{array}{l}\text { Push-up } \\
\text { Number }\end{array}$ & $\begin{array}{l}\text { Curl-up } \\
\text { Number }\end{array}$ & $\begin{array}{c}\text { sit } \\
\text { and reach } \\
(\mathrm{cm})\end{array}$ \\
\hline Very good & $>35$ & $>25$ & $>34$ & $>31.17$ \\
\hline Good & 26-35 & $17-25$ & 25-34 & 24.67-31.17 \\
\hline Average & $14-25$ & $08-16$ & $15-24$ & $16.55-24.66$ \\
\hline Poor & 04-13 & 01-07 & 05-14 & $10.6-16.54$ \\
\hline Very poor & $<04$ & $<1$ & $<5$ & $<10.6$ \\
\hline
\end{tabular}

Table 9.The following table is the norms for boys (17 years old students)

\begin{tabular}{|c|c|c|c|c|}
\hline Tests & $\begin{array}{c}\text { Pacer } \\
\text { (laps } \\
\text { competed) }\end{array}$ & $\begin{array}{l}\text { Push-up } \\
\text { Number }\end{array}$ & $\begin{array}{l}\text { Curl-up } \\
\text { Number }\end{array}$ & $\begin{array}{c}\text { sit } \\
\text { and reach } \\
(\mathrm{cm})\end{array}$ \\
\hline Very good & $>80$ & $>37$ & $>72$ & $>40.35$ \\
\hline Good & $58-80$ & 28-37 & 53-72 & $30.17-40.35$ \\
\hline Average & 30-57 & 14-27 & 27-52 & $17.43-30.16$ \\
\hline Poor & $8-29$ & 03-13 & $06-26$ & 7.24-17.42 \\
\hline Very poor & $<8$ & $<03$ & $<06$ & $<7.24$ \\
\hline
\end{tabular}

Table 10.The following table is the norms for girls (17 years old students)

\begin{tabular}{|c|c|c|c|c|}
\hline Tests & $\begin{array}{c}\text { Pacer } \\
\text { (laps } \\
\text { competed) }\end{array}$ & Push-up & Curl-up & $\begin{array}{c}\text { sit } \\
\text { and reach } \\
(\mathbf{c m})\end{array}$ \\
\hline $\begin{array}{c}\text { Level } \\
\text { Very good }\end{array}$ & $>42$ & $>25$ & $>32$ & $>30.03$ \\
\hline Good & $\mathbf{2 8 - 4 2}$ & $\mathbf{1 8 - 2 5}$ & $\mathbf{2 3 - 3 2}$ & $\mathbf{2 2 . 9 7 - 3 0 . 0 3}$ \\
\hline Average & $\mathbf{1 6 - 2 7}$ & $\mathbf{1 0 - 1 7}$ & $\mathbf{1 2 - 2 2}$ & $\mathbf{1 4 . 1 5 - 2 2 . 9 6}$ \\
\hline Poor & $\mathbf{0 6 - 1 5}$ & $\mathbf{0 2 - 0 9}$ & $\mathbf{0 3 - 1 1}$ & $\mathbf{0 8 - 1 4 . 1 4}$ \\
\hline Very poor & $<06$ & $<02$ & $<03$ & $<08$ \\
\hline & & & & \\
\hline
\end{tabular}

Table 11.The following table is the norms for boys (18 years old students)

\begin{tabular}{|c|c|c|c|c|}
\hline Tests & $\begin{array}{c}\text { Pacer } \\
\text { (laps } \\
\text { competed) }\end{array}$ & Push-up & Curl-up & $\begin{array}{c}\text { sit } \\
\text { and reach } \\
(\mathbf{c m})\end{array}$ \\
\hline $\begin{array}{c}\text { Level } \\
\text { Very good }\end{array}$ & $>102$ & $>40$ & $>72$ & $>41.07$ \\
\hline Good & $\mathbf{7 5 - 1 0 2}$ & $\mathbf{3 0 - 4 0}$ & $\mathbf{5 3 - 7 2}$ & $\mathbf{3 1 . 2 7 - 4 1 . 0 7}$ \\
\hline Average & $\mathbf{4 1 - 7 4}$ & $\mathbf{1 6 - 2 9}$ & $\mathbf{2 7 - 5 2}$ & $\mathbf{1 9 . 0 1 - 3 1 . 2 6}$ \\
\hline Poor & $\mathbf{1 3 - 4 0}$ & $\mathbf{0 4 - 1 5}$ & $\mathbf{0 6 - 2 6}$ & $\mathbf{9 . 2 0 - 1 9 . 0 0}$ \\
\hline Very poor & $<13$ & $<04$ & $<6$ & $<\mathbf{9 . 2 0}$ \\
\hline
\end{tabular}

Table 12.The following table is the norms for girls (18 years old students)

\begin{tabular}{|c|c|c|c|c|}
\hline Tests & $\begin{array}{c}\text { Pacer } \\
\text { (laps } \\
\text { competed) }\end{array}$ & Push-up & Curl-up & $\begin{array}{c}\text { sit } \\
\text { and reach } \\
(\mathbf{c m})\end{array}$ \\
$\begin{array}{c}\text { Level } \\
\text { Very good }\end{array}$ & $>34$ & $>21$ & $>30$ & $>30$ \\
\hline Good & $25-34$ & $14-21$ & $\mathbf{2 1 - 3 0}$ & $\mathbf{2 3 . 6 4 - 3 0}$ \\
\hline Average & $14-24$ & $07-13$ & $11-20$ & $\mathbf{1 5 . 8 9 - 2 3 . 6 3}$ \\
\hline Poor & $05-13$ & $01-06$ & $\mathbf{0 2 - 1 0}$ & $\mathbf{0 9 . 6 9 - 1 5 . 8 8}$ \\
\hline Very poor & $<05$ & $<01$ & $<02$ & $<\mathbf{0 9 . 6 9}$ \\
\hline
\end{tabular}

\section{Discussion}

From the results listed in the table (01-12) it is possible to know the standard grade and levels for every element of health-related physical fitness which helps identifying the level of health-related physical fitness as a basis for assessing and measuring individual and society's healthiness.

Looked at from the researchers' point of view, it's crucial that any instructor has to take use of these standard levels since they are one of the 
scientific bases of the objective assessment through which the instructor can evaluate and assess his students at any time in order to define every student's level in all tests.

In connection to this, scientists see the importance of having recourse to technology in assessing through the use of the computer in this process and setting exams thanks to the good facilities that the computer provides in bettering assessment and saving time and effort for both students and instructors. It has also a high capacity in storing data swiftly; therefore, it helps us in making objective decisions on the basis of accurate operations.

\section{Recommendations}

In light of the results of this study, researchers recommended to rely on a computer program to assess the health-related fitness for secondary stage students in Algeria and encourage students to use self-evaluation and monitoring their fitness healthrelated.

\section{Conclusion}

This is the first study in Algeria presenting the normative data, this data will facilitate the identification of adolescent with low fitness in order to determine appropriate targets and promote positive health behaviors. This software also helps in the evaluation of physical education and sports programs in the secondary phase, through to identify the extent to achieve the desired objectives, and what can be reconsidered in the objectives of this program and its content, if it is found unsuitable for the level of students' abilities and capabilities available.

\section{References}

[1] Mark. J. Catley, Grant. R. Tomkinson, "Normative health-related fitness values for children analysis of 85347 test results on 9-17-year-old", Br J Sports Med, 2013, 47, 98-108.

[2] Mark Hamer, Shreenidhi M. Venuraju, Avijit Lahiri, Amanda Rossi, Andrew Steptoe, "Objectively Assessed Physical Activity, Sedentary Time, and Coronary Artery Calcification in Healthy Older Adults", 2012 .

[3] World Health Organization, "Global recommendations on physical activity for health", Geneva: WHO Publications, 2010.

[4] Castelli DM, Hillman CH, Buck SM, Erwin HE "Physical Fitness and Academic Achievement in Thirdand Fifth-Grade Students", Journal of Sport \& Exercise Psychology, 2007, 29, 239-252.
[5] España-Romero, E. G. Artero, D. Jimenez-Pavón, M. Cuenca-Garcia, F. B. Ortega, J. Castro-Piñero, M. Sjö strom, M. J. Castillo-Garzon, J. R. Ruiz "Assessing health-related fitness tests in the school setting: reliability, feasibility and safety", The ALPHA Study, International Journal of Sports Medicine, 2010, 31 (7), 490-49.

[6] Ortega F.B, J.R. Ruiz, M.J. Castillo, and Sjöström M, "Physical fitness in childhood and adolescence: a powerful marker of health", International Journal of Obesity, 2008, 32, pp.1-11.

[7] ACSM's Health-Related Physical Fitness Assessment, Manual second edition, 2008.

[8] Baranowski T1, Bouchard C, Bar-Or O, Bricker T. Heath G, Kimm SY, Malina R, Obarzanek E, Pate R, Strong WB, and al, " Assessment, prevalence, and cardiovascular benefits of physical activity and fitness in youth”, Med Sci Sports Exerc, 1992, 237-47.

[9] Stair, Ralph M, and al, Principles of Information Systems, Sixth Edition, Thomson Learning, 2003.

[10] Hazzaa, (2004). 'Physical activity in the prevention of life style diseases', http:// faculty.ksu.edu.sa/hazzaa/ DocLib5/ (February 2013).

[11] ACSM's Guidelines for exercise Testing and Prescription. Eighth Edition, 2009.

[12] Jack H.Wilmore et al., Physiology of Sport and Exercise, De Boeck, 2009.

[13] Boiarskaia EA1, Boscolo MS, Zhu W, Mahar MT, "Cross-Validation of an Equating Method Linking Aerobic FITNESSGRAM ${ }^{\circledR}$ Field Tests", Am J Prev Med, 2011, 41(4S2):S124-S130.

[14] Roberto Ierusalimschy, Programming in Lua, Second Edition, 2006, ISBN 85-903798-2-5.

[15]'Health-Related Fitness Assessment Protocols', Research; http://www.edu.gov.mb.ca/k12/cur/physhlth/ guidelines/section4.pdf “, (September 2014).

\section{Appendices Test Descriptions}

\section{PACER}

The 20m PACER (Figure 6) estimates aerobic capacity from the number of laps (20m in distance) that are completed. Unlike the other two Aerobic Capacity options, the PACER starts out easy and becomes progressively more difficult. Students are instructed to run as long as possible across a distance and at a specified pace set to music played from a tape or CD. For this test, a set of parallel lines is drawn 20 meters apart. Students start on one line, run the distance, and touch the opposite line with one foot. Once they hear the sound of a single beep, students turn around and run back to the starting line. Every minute, indicated by a triple beep, the pace gets faster. Students continue in this 
manner until they fail twice to touch the line before they hear the single beep. In the proper administration of the PACER, a student is allowed two form breaks with the first form break counting as a lap. A student who commits two form breaks after the start of the PACER should be scored 1 .

\section{Push-Up [15]}

The Push-Up Test (Figure 7) is conducted as follows:

1. Lie on the floor (face down) with hands placed under the shoulders, fingers pointed forward, and legs straight and together with toes tucked under so that they are in contact with the floor. Then push until the arms are fully extended, keeping legs and back straight. This is the up position.

2. Lower the body using the arms, keeping the back in a straight line from head to toes until the elbows reach 90 degrees and the upper arms are parallel to the floor. This is the down position.

3 . The task begins in the up position. One complete push-up (repetition) is counted when the student completes a cycle of up-down-up at the specified pace.

4. Inability to keep pace with the "beeps" (of about one push-up every three seconds) or to maintain the correct form on two consecutive repetitions indicates the task is over.

5. The score is the total number of push-ups (repetitions) performed correctly without stopping.

\section{Body Mass Index [15]}

The Body Mass Index or Quetelet index (Figure 8), This task indicates a student's weight relative to his or her height.

1. Measure height.

2. Measure body mass (weight).

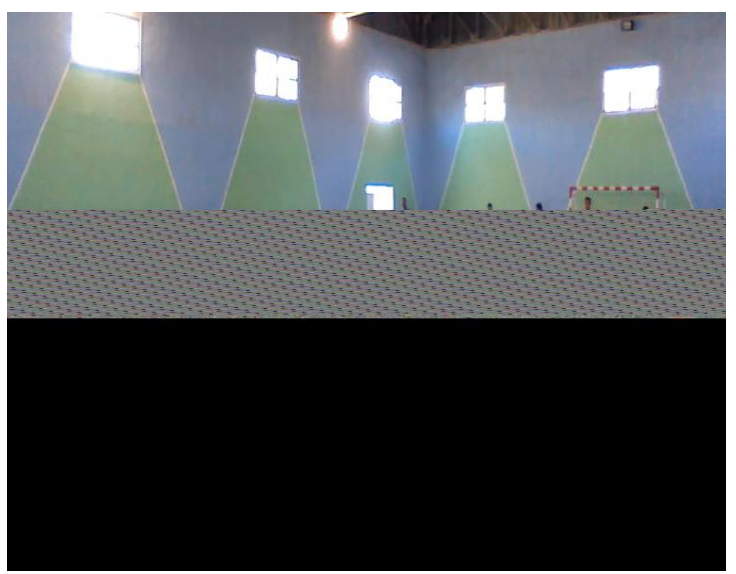

Figure 6. PACER 20m

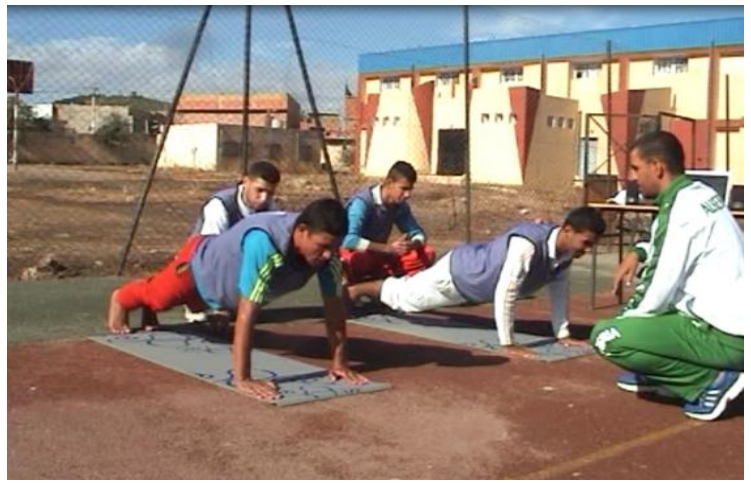

Figure 7. Push-Up

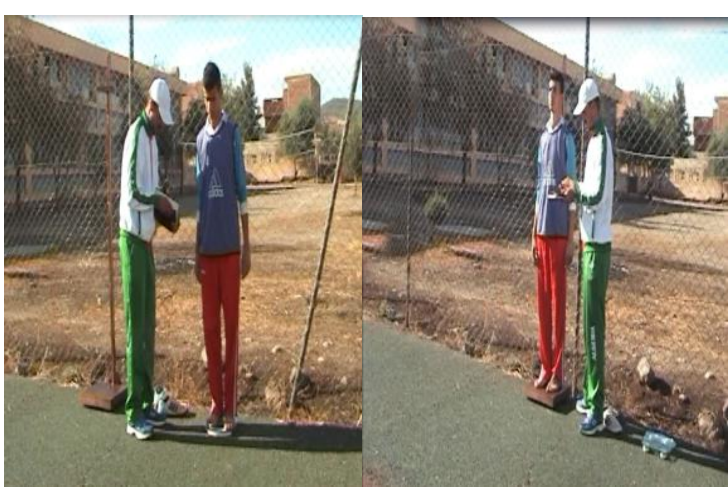

Figure 8. Body Mass Index

\section{Curl-Up [15]}

The curl-up Test (Figure 9) is conducted as follows: 1. Lie on back with knees flexed, feet flat on the mat, and heels between $30 \mathrm{~cm}$ (12 in) and $45 \mathrm{~cm}$ (18 in) from the buttocks.

2. Cross arms on chest with hands on the opposite shoulders.

3. The partner may hold the participant's feet down, applying only enough pressure to maintain feet contact with the floor.

4. Start on the command, "Ready...? Go."

5. Curl to a sitting position, maintaining hand contact with the shoulders.

The curl-up is completed when the elbows touch the thighs.

6. Do not continue the motion beyond 45 degrees (angle between floor and straight back). Do not bounce.

7. Return to the down position until the back contacts the mat.

8. One complete curl-up (repetition) is counted when a cycle of down-updown at the specified pace is completed.

9. Inability to keep pace with the "beeps" or to maintain the correct form on two consecutive repetitions indicates the assessment is over. 


\section{Modified Sit and Reach [15]}

The Modified Sit and Reach Test (Figure 10) are conducted as follows:

1. Take off shoes and sit with one leg fully extended. Place the sole of the foot flat against the back portion of the flexometer.

2. Flex (bend) the other leg, with the sole of the foot flat on the floor about 5 to $8 \mathrm{~cm}$ from inside of opposite leg.

3. Making sure hands are together (one atop the other, palms facing down), reach forward with arms evenly stretched, without jerking, and push along the measuring scale with the fingertips of both hands together.

4. Pushing as far forward as possible, hold this position for at least two seconds, and then return to the upright position.

5. Repeat the task three times and record the best score. Take the measurement to the nearest centimeter.

6. Repeat for the other leg.

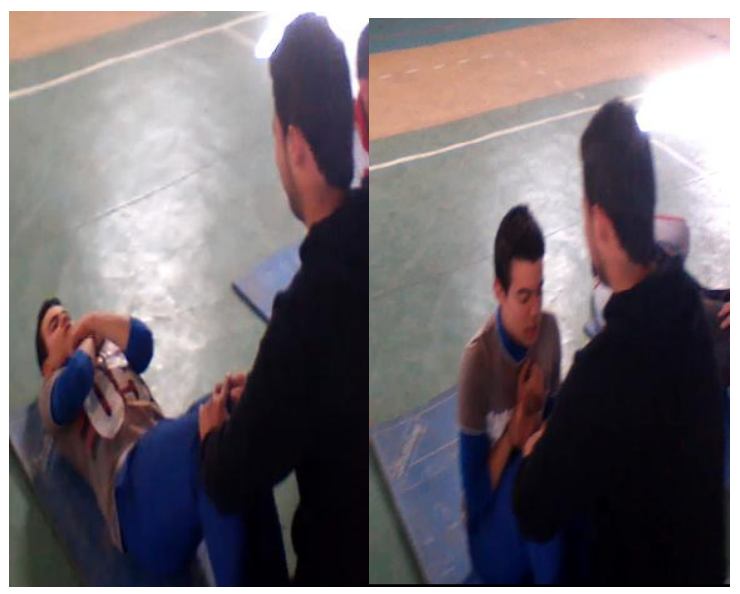

Figure 9. Curl-Up

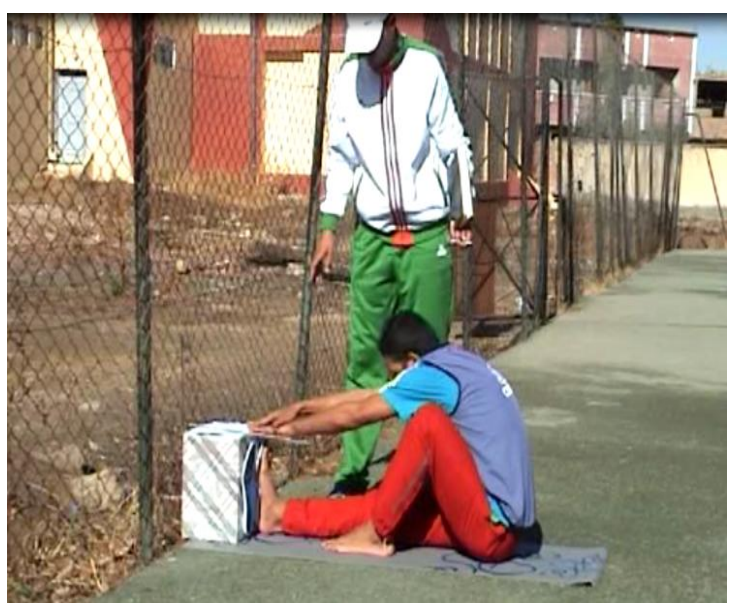

Figure 10. Modified Sit and Reach 